Syntax Idea: p-ISSN: 2684-6853 e-ISSN: 2684-883X

Vol. 3, No. 9, September 2021

\title{
ANALISIS PENGARUH FAKTOR-FAKTOR TERHADAP UNDERPRICING PADA PENAWARAN UMUM SAHAM PERDANA DI BURSA EFEK INDONESIA
}

\section{Moch. Irfandi, Sri Muljaningsih, Kiki Asmara}

Universitas Pembangunan Nasional (UPN) Veteran Jawa Timur, Indonesia

Email: muhamadirfandisky1407@gmail.com, muljaningsihsri@gmail.com, kikyasmara25@gmail.com

\begin{abstract}
Abstrak
Underpricing adalah sebuah fenomena Initial Public Offering (IPO) yang sering terjadi di pasar modal dan telah dibuktikan oleh para peneliti di berbagai negara. Penelitian ini bertujuan untuk mengetahui pengaruh debt to equity ratio, earning per share, umur perusahaan, return on assets pada underpricing yang terdaftar di Bursa Efek Indonesia pada periode 2015-2019. Penelitian ini menggunakan analisis regresi linier berganda dimana debt to equity ratio, earning per share, umur perusahaan, return on assets sebagai variabel bebas, dan underpricing sebagai variabel terikat. Penelitian ini menggunakan pendekatan kuantitatif dan data yang digunakan dalam penelitian ini yaitu data sekunder yang diambil dari data periodik underpricing yang terdaftar di Bursa Efek Indonesia pada tahun 2015 sampai 2019. Hasil pengujian menunjukkan bahwa variabel debt to equity ratio, earning per share berpengaruh positif dan signifikan terhadap underpricing, variabel umur perusahaan tidak berpengaruh terhadap underpricing dan variabel return on assets berpengaruh negatif dan signifikan terhadap underpricing.
\end{abstract}

Kata Kunci: debt to equity ratio; earning per share; umur perusahaan; return on assets; underpricing;

\section{Abstract}

Underpricing is an IPO phenomenon in the capital markets and have been proven by researchers in many countries. This study aims to determine the effect of debt to equity ratio, earnings per share, company age, return on assets on underpricing listed on the Indonesia Stock Exchange in the 2015-2019 period. This study uses multiple linear regression analysis where debt to equity ratio, earnings per share, company age, return on assets as independent variables, and underpricing as dependent variable. This study uses a quantitative approach and the data used in this study are secondary data taken from periodic underpricing data listed on the Indonesia Stock Exchange from 2015 to 2019. The test results show that the variable debt to equity ratio, earnings per share has a positive and significant effect. on underpricing, the firm age variable has no effect on underpricing and the variable return on assets has a negative and significant effect on underpricing.

Keywords: debt to equity ratio; earnings per share; company age; return on assets; underpricing

$\begin{array}{ll}\text { How to cite: } & \text { Irfandi, Moch., Muljaningsih, S., \& Asmara, K., (2021) Analisis Pengaruh Faktor-Faktor Terhadap } \\ & \text { Underpricing pada Penawaran Umum Saham Perdana Di Bursa Efek Indonesia. Syntax Idea, 3(9), } \\ & \text { https://doi.org/10.36418/syntax-idea.v3i9.1491 } \\ \text { E-ISSN: } & \text { 2684-883X } \\ \text { Published by: } & \text { Ridwan Institute }\end{array}$


Received: 2021-08-22; Accepted: 2021-09-05; Published: 2021-09-20

\section{Pendahuluan}

Adanya perkembangan dalam lingkungan bisnis pada saat ini tentunya akan menciptakan suatu kodisi persaingan yang ketat. Hal ini akan mengakibatkanperusahaan akan melakukan berbagai cara agar bisa bertahan bahkan tumbuh berkembang dalam iklim persaingan yang dihadapi. Demi mencapai pertumbuhan serta perkembangan yang diharapkan, perusahaan akan membutuhkan dana yang besar. Salah satu alternatif pendanaan dari luar perusahaan adalah melalui mekanisme penyertaan yang umumnya dilakukan dengan menjual saham perusahaan kepada publik atau sering dikenal dengan go public (Kurniasari, 2016). Menurut (Hayati \& Isynuwardhana, 2014) dalam proses go public, sebelum diperdagangkan di pasar sekunder, sahamterlebih dahulu dijual di pasar primer atau sering disebut pasar perdana. Penawaransaham secara perdana ke publik atau masyarakat melalui pasar perdana ini dikenaldengan istilah Initial Public Offering (IPO). Pada saat IPO (go public), perusahaan harus menyediakan suatu prospektus yang berisi laporan keuangan, maupun non keuangan, sesuai dengan ketentuan yang ditetapkan BAPEAM.

Penentuan harga saham yang akan ditawarkan pada saat IPO merupakan faktor penting, baik bagi emiten maupun underwriter karena berkaitan dengan jumlah dana yang akan diperoleh emiten dan risiko yang akan ditanggung oleh underwriter. Jumlah dana yang diterima emiten adalah perkalian antara jumlah saham yang ditawarkan dengan harga per saham, sehingga semakin tinggi harga persaham maka dana yang diterima akan semakin besar. Hal ini mengakibatkan emitenseringkali menentukan harga saham yang dijual pada pasar perdana dengan membuka penawaran harga yang tinggi, karena menginginkan pemasukan dana semaksimal mungkin. Apabila harga saham pada pasar perdana (IPO) lebih rendah dibandingkan dengan harga saham pada pasar sekunder pada hari pertama, maka akan terjadi fenomena harga rendah di penawaran perdana, yang disebut underpricing. Sebaliknya, apabila harga saat IPO lebih tinggi dibandingkan denganharga saham pada pasar sekunder pada hari pertama, maka fenomena ini disebut overpricing (Kristiantari, 2013).

Masalah yang seringkali timbul dari kegiatan IPO adalah terjadinya underpricing yang menunjukkan bahwa sebenarnya harga saham pada waktu penawaran perdana relatif lebih rendah dibanding pada saat diperdagangkan di pasar sekunder. Pada saat perusahaan melakukan IPO, harga saham yang dijual pasar perdana ditentukan berdasarkan kesepakatan antara perusahaan emiten dan penjamin emisi (underwriter), sedangkan harga yang terjadi di pasar sekunder ditentukan oleh mekanisme pasar yang telah ada melalui kekuatan permintaan dan penawaran saham tersebut di pasar modal. Apabila harga saham pada saat IPO lebih rendah dibandingkan dengan harga saham di pasar sekunder hari pertama, maka akan terjadi underpricing (Risqi \& Harto, 2013).

Menurut (Wijayanto, 2010) melihat underpricing dari IPO sebagai alat bantu yang digunakan oleh perusahaan untuk memberi sinyal tentang kualitas baik mempunyai 
insentif untuk melakukan underpricing pada IPO.Perusahaan dapat menawarkan harga sahamnya lebih baik pada penawaran berikutnya. Dengan demikian total penawaran yang diterima perusahaan dari pasarIPO ditambah dari pasar saham berikutnya lebih besar dibandingkan dengan penerbitan saham IPO yang tidak dilakukan underprice.

Fenomena underpricing yang muncul adalah pasar menganggap dengan underpricing yang besar perusahaan tidak dimasukkan dalam perusahaan perusahaan unggulan. Sebaliknya underpricing yang kecil dipercaya akan menarik minat investor karena yakin akan kualitas perusahaan. Jadi perusahaan yang melakukan IPO tentunya berharap untuk dapat memperkecil nilai underpricingnya, agar dapat mencerminkan sebagai perusahaan yang berkualitas.

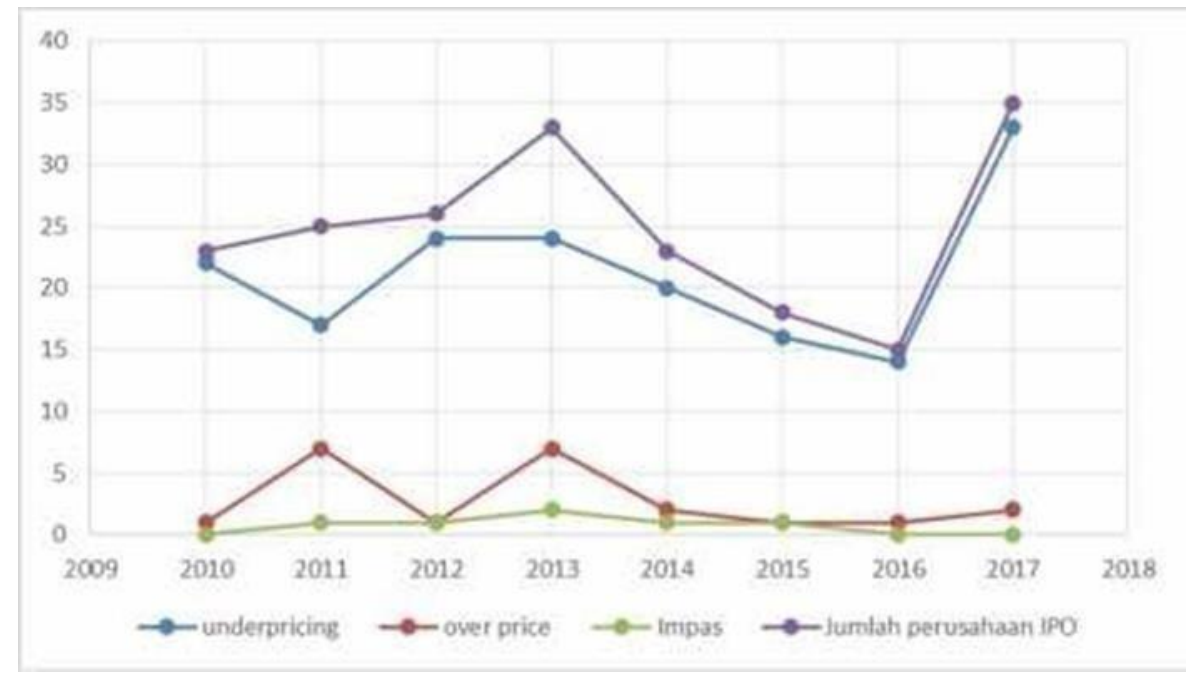

Gambar 1

Fenomena Underpricing dan Overpricing 2010-2017.

Alasan penulis memilih judul penelitian ini karena dalam penelitian ini terdapat masalah yang harus diselesaikan dengan menggunakan analisis data. Masalah tersebut antara lain terjadinya underpricing yang menunjukkan bahwa sebenarnya harga saham pada waktu penawaran perdana relatif lebih rendah dibanding pada saat diperdagangkan di pasar sekunder.

Penulis memilih variabel independen Debt To Equity Ratio, Earning per Share, Umur Perusahaan, dan Return On Assets karena banyak peneliti terdahulu yang menggunakan variabel tersebut dengan hasil yang berbeda, maka dari itu penulis ingin mencoba melakukan penelitian ini dengan variabel tersebut agar dapat mengetahui secara pasti hasil apa yang diperoleh dari penelitian tersebut (Astuti, 2012). Terdapat beberapa perbedaan penelitian yang dilakukan oleh penelitian sekarang dengan penelitian terdahulu yang meliputi perbedaan pada variabel penelitian terutama variabel independen, periode penelitian dan objek penelitian yang akan diteliti oleh karena itu dalam penelitian ini, variabel independennya ada empat yaitu DER, EPS, Umur Perusahaan, dan ROA. Sedangkan variabel dependennya tingkat Underpricing. 
Berdasarkan Latar Belakang yang telah diuraikan diatas, maka diperoleh tujuan dalam penelitian ini sebagai berikut: 1) Untuk mengetahui pengaruh Debt To Equity Ratio Terhadap Underpricing diBursa Efek Indonesia, 2) Untuk mengetahui pengaruh Earning per Share Terhadap Underpricing di Bursa Efek Indonesia, 3) Untuk mengetahui pengaruh Umur Perusahaan Terhadap Underpricing di BursaEfek Indonesia, 4) Untuk mengetahui pengaruh Return On Assets Terhadap Underpricing di Bursa Efek Indonesia.

Dan manfaat yang diperoleh dari penelitian ini yaitu diharapkan hasil penelitian ini dapat digunakan untuk menambah referensi yang dapat memberikan informasi bagi kemungkinan adanya penelitian lebih lanjut. Bagi kalangan akademis, diharapkan dapat menambah pengetahuan dan dijadikan acuan untuk penelitian serupa di masa yang akan datang. Bagi peneliti, diharapkan dapat membantu untuk menambah wacana dan referensi baik secara teori maupun praktek khususnya mengenai perbandingan underpricing pada penawaran saham perdana perusahaan di Bursa Efek Indonesia (BEI) sehingga dapat bermanfaat bagi penelitian selanjutnya yang terkait dan sejenis.

\section{Metode Penelitian}

Pendekatan penelitian ini menjelaskan tentang seluruh aspek penelitian yang digunakan. Penelitian ini menggunakan pendekatan kuantitatif. Pendekatan kuantitatif ini menjelaskan apakah terdapat hubungan antar variabel dalam penelitian dan menguji hipotesis yang diteliti.

Tempat pelaksanaan penelitian ini di Bursa Efek Indonesia dan waktu yangdigunakan untuk melakukan penelitian ini dilakukan pada tahun 2015-2019. Definisi operasional dan pengukuran variabel menjelaskan pernyataan tentang pengoperasian pada suatu konsep penelitian dalam bentuk variabel dan satuan pengukurannya. Dalam penelitian ini akan membuktikan hubungan antara variabel dependen (Underpricing) dengan variabel independen (Debt to Equity Ratio, Earning per Share, Umur Perusahaan, dan Return On Assets).

Metode pengumpulan data yang dipakai yaitu dengan menggunakan metode dokumentasi, yaitu dengan mencatat dan mengcopy data-data tertulis yang berhubungan dengan masalah penelitian baik dari sumber dokumen/buku-buku, koran, majalah, internet dan lain lain mengenai tingkat Underpricing, Debt to Equity Ratio, Earning per Share, Umur Perusahaan, dan Return On Assets berupa data tahunan.

Teknik analisis data yang digunakan dalam penelitian ini adalah dengan menggunakan analisis regresi linier berganda untuk mendapatkan penjelasan yang menyeluruh hubungan antara variabel independen yakni Debt to Equity Ratio (DER), Earning per Share (EPS), Umur Perusahaan, dan Return On Assets (ROA) terhadap variabel dependen yakni tingkat Underpricing di Bursa Efek Indonesia 


\section{Hasil dan Pembahasan}

\section{A. Hasil Penelitian}

\section{Uji Asumsi Klasik (BLUE)}

Untuk menentukan persamaan regresi dengan metode kuadrat terkecil (Ordinary Least Square) layak digunakan dalam analisis. Uji asumsi klasik dilakukan untuk memperoleh hasil yang valid, sehingga persamaan regresi bersifat Best Linier Unbiased Estimator (BLUE). Data yang diolah memenuhi 4 asumsi klasik, yaitu uji normalitas, uji multikolinieritas, uji heteroskesdasitas, dan uji autokorelasi (Laeli, 2016)

2. Uji Normalitas

Menurut (Sutanto, Ghozali, \& Handayani, 2018) dasar pengambilan keputusan dilihat dari jika data menyebar disekitar garis diagonal dan mengikuti arah garis diagonal atau grafik histogramnya menunjukkan pola distribusi normal, maka model regresi memenuhi asumsi normalitas. Sedangkan jika data menyebar jauh dari diagonal dan atau tidak mengikuti arah garis diagonal atau grafik histogram tidak menunjukkan pola distribusi normal, maka model regresi tidak memenuhi asumsi normalitas.

Menurut (Indarto \& Ghozali, 2016) dasar pengambilan keputusan bisa dilakukan berdasarkan profitabilitas (Asymtitic Significance), yaitu:

1. Jika profitabilitas $>0,05$ maka distribusi dari populasi adalah normal.

2. Jika profitabilitas $<0,05$ maka populasi tidak didistribusi secara normal.

Selain itu uji normalitas digunakan untuk mengetahui bahwa data yang diambil berasal dari populasi berdistribusi normal. Uji yang digunakanuntuk menguji kenormalan adalah uji Kolmogorov-Smirnov. Berdasarkan sampel ini akan diuji hipotesis nol bahwa sampel tersebut berasal dari populasi berdistribusi normal melawan hipotesis tandingan bahwa populasi berdistribusi tidak normal.

3. Uji Multikolinieritas

Menurut (Indarto \& Ghozali, 2016) uji multikolinieritas bertujuan untuk mengetahui apakah dalam modelregresi berganda ditemukan adanya korelasi antar variabel bebas atau tidak. Model yang baik seharusnya tidak terjadi korelasi yang tinggi diantara variabel bebas. Jika variabel bebas saling berkorelasi, maka variabel variabel ini tidak orthogonal (nilai korelasi tidak sama dengan nol). Uji multikolinieritas ini dapat dilihat dari nilai tolerance dan Variance Inflation Factor (VIF).

Tolerance mengukur variabel bebas terpilih yang tidak dapatdijelaskan oleh variabel lainnya. Jadi nilai tolerance yang rendah sama dengan nilai VIF yang tinggi (karena VIF $=1 /$ tolerance) dan menunjukkan adanya kolinieritas yang tinggi. Nilai cut off yang umum dipakai adalah nilai tolerance 0,10 atau nilai VIF 10. Jadi multikolinieritas terjadi tolerance $<0,10$ atau nilai VIF $>10$. Dasar pengambilan keputusan untuk uji multikolinieritas adalah:

1. Jika antar variabel bebas pada korelasi diatas 0,90 , maka hal inimerupakan adanya multikolinieritas. 
2. Multikolinieritas juga dapat dilihat dari VIF, Jika VIF $<10$ makadalam data tidak terdapat multikolinieritas, dengan rumus :

$$
\mathrm{VIF}=\frac{1}{1-R \mathrm{i} 2}
$$

Sumber: (Barusman \& Yoshoa, 2014) Nilai Eigen Value berjumlah satu atau lebih, jika variabel bebasmendekati 0 menunjukkan adanya multikolineritas.

\section{Uji Heteroskedastisitas}

Uji heteroskedastisitas bertujuan untuk menguji apakah dalam modelregresi terjadi ketidaksamaan variance dari residual satu pengamatan kepengamatan yang lain (Indarto \& Ghozali, 2016). Model regresi yang baik adalah yang terjadi homokedastisitas atau tidak terjadi heteroskedastisitas. Bila terjadi heteroskedastisitas akan menimbulakan varians koefisien regresi menjadi minimal dan confidence interval melebar, sehingga hasil uji signifikansi statistik tidak valid lagi. Cara mengetahui ada tidaknya heteroskedastisitas adalah dengan menggunakan uji spearman dengan spss. Hipotesis dalam uji heteroskesdastisitas dengan menggunakan uji spearman adalah sebagai berikut:

1. Terjadi masalah heterokesdastisitas jika nilai signifikansi Sig. (2- tailed) $<0,05$

2. Sebaliknya tidak terjadi masalah heterokesdastisitas jika signifikansi Sig. (2tailed) $>0,05$

5. Uji Autokorelasi

Menurut (Indarto \& Ghozali, 2016) menyatakan bahwa uji autokolerasi adalah untuk menguji apakah dalam model regresi linier ada korelasi antara kesalahan pengganggu pada periode $t$ dengan kesalahan pengganggu periode $t-1$ (sebelumnnya).

Untuk data cross section, akan diuji apakah terdapat hubungan yangkuat di antara data pertama dan ke dua, data ke dua dengan ke tiga dan seterusnya. Jika ya, telah terjadi autokolerasi. Hal ini akan menyebabkan informasi yang diberikan menjadi menyesatkan. Oleh karena itu, perlu tindakan agar tidak terjadi autokolerasi. Pada pengujian autokolerasi digunakan uji Durbin-Waston untuk mengetahui ada tidaknya autokolerasi pada model regresi dan berikut nilai Durbin- Waston yang diperoleh melaluihasil estimasi model regresi (Husaeni, 2019).

Menurut (Indarto \& Ghozali, 2016) dasar yang digunakan untuk pengambilan keputusan secara umum adalah sebagai berikut:

\section{Tabel 1}

Model Durbin-Waston

\begin{tabular}{lcc}
\hline \multicolumn{1}{c}{ Hipotesisnol } & Keputusan & Jika \\
\hline Tidak ada auto korelasi positif & Tolak & $0<\mathrm{d}<\mathrm{Cl}$ \\
\hline Tidak ada auto korelasi positif & No Decision & $\mathrm{dl} \leq \mathrm{d} \leq \mathrm{du}$ \\
\hline Tidak ada korelasi negative & Tolak & $4-\mathrm{dl}<\mathrm{d}<4$ \\
\hline
\end{tabular}




\begin{tabular}{lcc}
\hline Tidak ada korelasi negative & No Decision & 4-du $\leq \mathrm{d} \leq 4-\mathrm{dl}$ \\
$\begin{array}{l}\text { Tidak ada auto korelasi positif atau } \\
\text { Negative }\end{array}$ & Tidak ditolak & $\mathrm{du}<\mathrm{d}<4$-du \\
\hline
\end{tabular}

Sumber: Imam Ghozali (2016:108)

\section{Analisis Regresi Linear Berganda}

Analisis regresi pada dasarnya adalah studi mengenai ketergantungan variabel dependen (terikat) dengan satu atau lebih variabel independen (variabel bebas), dengan tujuan untuk mengestimasi dan/atau memprediksi rata-rata populasi atau nilai rata-rata variabel dependen berdasarkan nilai variabel independen yang diketahui (Indarto \& Ghozali, 2016).

Penelitian ini menggunakan teknik analisis data dengan metode analisis Regresi Linear Berganda (Multiple Linear Regression). Analisis ini secara matematis ditulis dengan persamaan sebagai berikut :

$\mathrm{Y}=\mathrm{a}+\mathrm{b} 1 \mathrm{X} 1+\mathrm{b} 2 \mathrm{X} 2+\mathrm{b} 3 \mathrm{X} 3+\mathrm{b} 4 \mathrm{X} 4+\mathrm{e}$

Sumber : (Howitt \& Cramer, 2017)

Keterangan :

$\mathrm{Y}=$ Tingkat Underpricing

a = Nilai Konstanta

$\mathrm{b} \quad=$ Koefisien Regresi dan Variabel Bebas

$\mathrm{X} 1$ = Debt To Equity Ratio

$\mathrm{X} 2$ = Earning per Share

$\mathrm{X} 3$ = Umur Perusahaan

X4 = Return On Assets

$\mathrm{e} \quad=$ standar error / kesalahan

\section{Uji Asumsi Klasik Uji Normalitas}

a. Pendekatan Grafik

Menurut (Sutanto et al., 2018) dasar pengambilan keputusan dilihat dari jika data menyebar disekitar garis diagonal dan mengikuti arah garis diagonal atau grafik histogramnya menunjukkan pola distribusi normal, maka model regresi memenuhi asumsi normalitas. Sedangkan jika data menyebar jauh dari diagonal dan atau tidak mengikuti arah garis diagonal atau grafik histogram tidak menunjukkan pola distribusi normal, maka model regresi tidak memenuhi asumsi normalitas. 


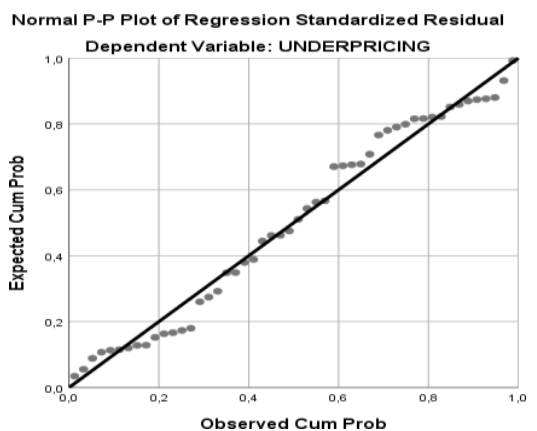

(Sumber : Output spss)

Gambar 1

Grafik Normal P-P Plot

\section{b.Pendekatan Kolmogorov-Smirnov}

Kriteria untuk menentukan yaitu bila nilai signifikan > 0.05 maka data berdistribusi normal, sedangkan bila nilai signifikan $<0.05$ maka data tersebut tidak berdistribusi normal.

Tabel 2

Uji Pendekatan Kolmogorov-Smirnov

\begin{tabular}{llr}
\hline \multicolumn{3}{c}{ One-Sample Kolmogorov-Smirnov Test } \\
\hline & \multicolumn{2}{c}{$\begin{array}{c}\text { Unstandardized } \\
\text { Residual }\end{array}$} \\
\hline $\mathrm{N}$ & & 50 \\
\hline Normal Parameters ${ }^{\text {a,b }}$ & Mean &, 0000000 \\
\cline { 2 - 3 } & Std. Deviation & 4146,7271944 \\
& & 6 \\
\hline Most Extreme & Absolute &, 110 \\
\cline { 2 - 3 } Differences & Positive &, 110 \\
\cline { 2 - 3 } & Negative &,- 097 \\
\hline Test Statistic &, 110 \\
\hline Asymp. Sig. (2-tailed) &, $175^{\mathrm{c}}$ \\
\hline a. Test distribution is Normal. \\
\hline \multicolumn{2}{l}{ b. Calculated from data. } \\
\hline \multicolumn{2}{c}{ c. Lilliefors Significance Correction. } \\
\hline \multicolumn{3}{c}{ (Sumber: output spss) } \\
\hline
\end{tabular}

Berdasarkan tabel dapat diketahui bahwa besarnya nilai asymp. sig. (2tailed) sebesar $0.175>0.05$, hal ini sesuai dengan ketentuan yang telah ditetapkan, maka dapat disimpulkan bahwa data pada tabel diatas dapat berdistribusi normal dan dapat digunakan dalam penelitian.

\section{Uji Multikolinearitas}

Uji multikolinieritas bertujuan untuk mengetahui apakah dalam model regresi berganda ditemukan adanya korelasi antar variabel bebas atau tidak (Indarto \& Ghozali, 2016). Uji multikolinieritas ini dapat dilihat dari nilai tolerance dan Variance Inflation Factor (VIF). 
Tolerance mengukur variabel bebas terpilih yang tidak dapat dijelaskan oleh . variabel lainnya. Jadi nilai tolerance yang rendah sama dengan nilai VIF yang tinggi (karena VIF $=1 /$ tolerance) dan menunjukkan adanya kolinieritas yang tinggi. Nilai cut off yang umum dipakai adalah nilai tolerance 0,10 atau nilai VIF 10. Jadi multikolinieritas terjadi tolerance $<0,10$ atau nilai VIF $>10$.

Tabel 3

Uji Multikolinearitas

\begin{tabular}{ccccc}
\hline \multirow{2}{*}{ Model } & \multicolumn{3}{c}{ Collinearity Statistics } & \\
& & Tolerance & VIF & Keterangan \\
\hline 1 & (Constant) & & & \\
DER & 0,989 & 1,001 & Tidak terjadi multikolinieritas \\
& EPS & 0,887 & 1,127 & Tidak terjadi multikolinieritas \\
& UP & 0,965 & 1,036 & Tidak terjadi multikolinieritas \\
& ROA & 0,887 & 1,127 & Tidak terjadi multikolinieritas \\
\hline
\end{tabular}

a. Dependent Variable: UP

(Sumber : output spss)

Berdasarkan hasil dari tabel 3 diketahui bahwa hasil perhitungan nilai tolerance untuk tiap-tiap variabel menunjukkan bahwa semua variabel independen memiliki nilai lebih dari 0.1. Hasil perhitungan dari nilai VIF juga menunjukkan bahwa variabel independent memiliki nilai kurang dari 10. Jadi, dapat disimpulkan bahwa tidak ada multikolinieritas antara variabel independen dalam persamaan satu diatas.

\section{Uji Heterokedastisitas}

Uji heteroskedastisitas bertujuan untuk menguji apakah dalam model regresi terjadi ketidaksamaan variance dari residual satu pengamatan ke pengamatan yang lain (Indarto \& Ghozali, 2016). Cara mengetahui ada tidaknya heteroskedastisitas adalah dengan menggunakan uji spearman dengan spss.

\section{Gambar 4}

\section{Uji Heretoskedastisitas}

\begin{tabular}{|c|c|c|c|c|c|c|c|c|}
\hline \multicolumn{9}{|c|}{ Correlation } \\
\hline & & & Der & Eps & Up & Roa & $\begin{array}{l}\text { Unde } \\
\text { rp } \\
\text { Ricin } \\
\text { g }\end{array}$ & $\begin{array}{l}\text { Unstandariz } \\
\text { ed Residual }\end{array}$ \\
\hline \multirow[t]{5}{*}{$\begin{array}{l}\text { Spearman } \\
\text { s Rha }\end{array}$} & \multirow[t]{3}{*}{ Der } & $\begin{array}{l}\text { Correlatio } \\
\mathrm{n} \\
\text { Coeficient }\end{array}$ & $\begin{array}{l}1.00 \\
0\end{array}$ & 154 & 050 & 051 & 140 & 055 \\
\hline & & $\begin{array}{l}\text { Sig (2- } \\
\text { Tailed) }\end{array}$ & & 284 & 732 & 726 & 333 & 706 \\
\hline & & $\mathrm{N}$ & 50 & 50 & 50 & 50 & 50 & 50 \\
\hline & \multirow[t]{2}{*}{ Eps } & $\begin{array}{l}\text { Correlatio } \\
\mathrm{n} \\
\text { Coeficient }\end{array}$ & 154 & $\begin{array}{l}1.00 \\
0\end{array}$ & 352 & 536 & 312 & 109 \\
\hline & & Sig (2- & 284 & & 012 & 000 & 027 & 452 \\
\hline
\end{tabular}




\begin{tabular}{|c|c|c|c|c|c|c|c|}
\hline & & \multicolumn{3}{|c|}{ Correlation } & \multirow[b]{2}{*}{ Roa } & \multirow[b]{2}{*}{$\begin{array}{l}\text { Unde } \\
\text { rp } \\
\text { Ricin } \\
\text { g } \\
\end{array}$} & \\
\hline & & Der & Eps & Up & & & $\begin{array}{l}\text { Unstandariz } \\
\text { ed Residual }\end{array}$ \\
\hline & \multicolumn{7}{|l|}{ Tailed) } \\
\hline & $\mathrm{N}$ & 50 & 50 & 50 & 50 & 50 & 50 \\
\hline \multirow[t]{3}{*}{$\mathrm{Up}$} & $\begin{array}{l}\text { Correlatio } \\
\mathrm{n} \\
\text { Coeficient }\end{array}$ & 050 & 352 & $\begin{array}{l}1.00 \\
0\end{array}$ & -140 &,- 126 &,- 055 \\
\hline & $\begin{array}{l}\text { Sig (2- } \\
\text { Tailed) }\end{array}$ & 732 & 012 & & 332 & 383 & 703 \\
\hline & $\mathrm{N}$ & 50 & 50 & 50 & 50 & 50 & 50 \\
\hline \multirow[t]{3}{*}{ Roa } & $\begin{array}{l}\text { Correlatio } \\
\mathrm{n} \\
\text { Coeficient }\end{array}$ & 051 & 536 & -140 & $\begin{array}{l}1.00 \\
0\end{array}$ & 267 & 021 \\
\hline & $\begin{array}{l}\text { Sig (2- } \\
\text { Tailed) }\end{array}$ & 7.26 & 000 & 332 & & 043 & 882 \\
\hline & $\mathrm{N}$ & 50 & 50 & 50 & 50 & 50 & 50 \\
\hline \multirow[t]{3}{*}{$\begin{array}{l}\text { Underp } \\
\text { Ricing }\end{array}$} & $\begin{array}{l}\text { Correlatio } \\
\mathrm{n} \\
\text { Coeficient }\end{array}$ & 140 & $\begin{array}{l}- \\
, 312\end{array}$ & $\begin{array}{l}- \\
, 126\end{array}$ & -267 & 1.000 & 900 \\
\hline & $\begin{array}{l}\text { Sig (2- } \\
\text { Tailed) }\end{array}$ & 333 & 027 & 383 & 043 & & 000 \\
\hline & $\mathrm{N}$ & 50 & 50 & 50 & 50 & 50 & 50 \\
\hline \multirow[t]{3}{*}{$\begin{array}{l}\text { Unstandarize } \\
\text { d Residual }\end{array}$} & $\begin{array}{l}\text { Correlatio } \\
\mathrm{n} \\
\text { Coeficient }\end{array}$ & 055 & $-\overline{-}$ &,- 055 & 021 & 900 & 1.000 \\
\hline & $\begin{array}{l}\text { Sig (2- } \\
\text { Tailed) }\end{array}$ & 706 & 452 & 703 & 882 & 000 & \\
\hline & $\mathrm{N}$ & 50 & 50 & 50 & 50 & 50 & 50 \\
\hline
\end{tabular}

Dari output di atas di ketahui bahwa nilai signifikansi atau sig. (2- tailed) variabel Debt To Equity Ratio (X1) sebesar 0,706, Earning per Share (X2) sebesar 0,452, Umur Perusahaan(X3) sebesar 0,703 dan Return On Assets (X4) sebesar 0,882. Karena nilai semua variabel tersebut lebih besar dari nilai 0,05 sehingga dapat di simpulkan bahwa tidak terdapat masalah heteroskedastisitas. Artinya model regresi yang di pakai penelitian layak untuk di lakukan.

\section{Uji Autokorelasi}

Uji autolorelasi bertujuan menguji apakah dalam model regresi linier ada korelasi antara kesalahan pengganggu pada periode $t$ dengan kesalahan pengganggu pada periode t-1 / sebelumnya (Indarto \& Ghozali, 2016) 
Tabel 5

Uji Autokorelasi

\begin{tabular}{|c|c|c|c|c|c|}
\hline \multicolumn{6}{|c|}{ Model Summary } \\
\hline Model & $\mathbf{R}$ & $\begin{array}{r}\mathbf{R} \\
\text { Square }\end{array}$ & $\begin{array}{l}\text { Adjuste } \\
\text { d R } \\
\text { Square }\end{array}$ & $\begin{array}{l}\text { Std. } \\
\text { Error of } \\
\text { the } \\
\text { Estimate }\end{array}$ & $\begin{array}{l}\text { Durbin- } \\
\text { Watson }\end{array}$ \\
\hline 1 & $.355^{\mathrm{a}}$ & .874 & .048 & $\begin{array}{l}41.0428 \\
6\end{array}$ & 2.030 \\
\hline
\end{tabular}

a. Predictors: (Constant), ROA, DER, UP, EPS

b. Dependent Variable: UNDERPRICING

11. Uji F

(Sumber: output spss)

Uji statistik F pada dasarnya menujukkan apakah variabel independen yang dimasukkan dalam model mempunyai pengaruh secara simultan terhadap variabel dependen (Indarto \& Ghozali, 2016).

Tabel 6

Uji Statistik F

\begin{tabular}{lllrllc}
\hline \multicolumn{7}{c}{ ANOVA } \\
\hline \multirow{2}{*}{ Model } & & $\begin{array}{l}\text { Sum of } \\
\text { Squares }\end{array}$ & $\begin{array}{l}\text { D } \\
\text { f }\end{array}$ & $\begin{array}{l}\text { Mean } \\
\text { Square }\end{array}$ & F & Sig \\
\hline \multirow{2}{*}{1} & Regression & 228916872,141 & 4 & 57229218,035 & 3,056 & $0^{026^{\mathrm{b}}}$ \\
\cline { 2 - 8 } & Residual & 842571974,839 & 45 & 18723821,663 & & \\
\cline { 2 - 8 } & Total & 1071488846,980 & 49 & & & \\
\hline
\end{tabular}

a. Dependent Variable: UNDERPRICING

b. Predictors: (Constant), EPS, ROA, DER, UP

(Sumber: output spss)

Dari tabel 6 dapat diketahui bahwa nilai $\mathrm{F}$ hitung sebesar 3,056 dengan signifikansi $0,026<0,05$, artinya variabel Debt To Equity Ratio, Earning per Share, Umur Perusahaan dan Return On Assets secara simultan memiliki pengaruh yang signifikan terhadap variabel Underpricing, sehingga model tersebut dinyatakan layak/fit.

\section{Uji T}

Uji $\mathrm{t}$ digunakan untuk menguji pengaruh masing-maising variabel independen yang digunakan terhadap variabel dependen secara parsial (Indarto \& Ghozali, 2016). Uji t dilakukan dengan melihat signifikansi t masing-masing variabel pada output hasil regresi dengan signifikansi $0,05(\mathrm{a}=5 \%)$. Kriteria pengambilan keputusannya adalah jika hasil signifikansi > 0,05 maka hipotesis ditolak (koefisien regresi tidak signifikan) dan sebaliknya. Untuk menguji hipotesis dalam penelitian dilakukan estimasi pada standardized coefficient dan p-value untuk masing- masing koefisien yang dapat dilihat pada tabel berikut: 
Tabel 7

Uji T Coefficients

\begin{tabular}{|c|c|c|c|c|c|c|}
\hline \multicolumn{2}{|c|}{ Model } & \multicolumn{2}{|c|}{$\begin{array}{l}\text { Unstandardized } \\
\text { Coefficients }\end{array}$} & \multirow{2}{*}{$\begin{array}{l}\text { Standardi } \\
\text { zed } \\
\text { Coefficien } \\
\text { ts } \\
\text { Bet } \\
\text { a }\end{array}$} & \multirow[t]{2}{*}{$\mathbf{T}$} & \multirow[t]{2}{*}{ Sig. } \\
\hline & & B & Std. Error & & & \\
\hline \multirow[t]{5}{*}{1} & (Constant) & 85.578 & 15.272 & & 2.772 & .000 \\
\hline & DER & .542 & .531 & .272 & 2.018 & .050 \\
\hline & EPS & .003 & .041 & .316 & 2.210 & .030 \\
\hline & UP & .461 & .467 & .069 & .483 & .631 \\
\hline & ROA & -.538 & .608 & -.192 & -2.242 & .020 \\
\hline
\end{tabular}

(Sumber : output spss)

Berdasarkan tabel 7 dapat diperoleh hasil perhitungan $\mathrm{t}$ beserta tingkat signifikansi dengan penjelasan sebagai berikut: 1. Pengaruh DER terhadap Underpricing memiliki t hitung sebesar 2,018 dengan nilai signifikansi 0.050, maka disimpulkan bahwa DER berpengaruh positif dan signifikan terhadap Underpricing. 2. Pengaruh EPS terhadap Underpricing memiliki t hitung sebesar 2,210 dengan nilai signifikansi 0.030, maka disimpulkan bahwa EPS berpengaruh positif dan signifikan terhadap Underpricing. 3. Pengaruh UP terhadap Underpricing memiliki t hitung sebesar 0,483 dengan nilai signifikansi 0.631, maka disimpulkan bahwa UP tidak berpengaruh signifikan terhadap Underpricing. 4. Pengaruh ROA terhadap Underpricingmemiliki t hitung sebesar -2,242 dengan nilai signifikansi 0.020, maka disimpulkan bahwa ROA berpengaruh negarif dan signifikan terhadap Underpricing.

\section{Uji Koefisien Determinasi Berganda (R2)}

Koefisien determinasi pada intinya mengukur seberapa jauh kemampuan sebuah model menerangkan variasi variabel terikat. Nilai koefisien determinasi adalah antara nol dan satu. Nilai R2 yang kecil atau mendekati 0 berarti kemampuan variabel-variabel bebas dalam menjelaskan variabel terikat sangat terbatas. Sedangkan nilai yang mendekati 1 berarti variabel- variabel bebas memberikan hampir semua informasi yang dibutuhkan untuk memprediksi variabel terikat (Indarto \& Ghozali, 2016).

Tabel 8

Uji Koefisien Determinasi

Berganda

\begin{tabular}{lcccr}
\hline \multicolumn{5}{c}{ Model Summary $^{\mathbf{b}}$} \\
\hline Model & $\mathrm{R}$ & R Square & $\begin{array}{c}\text { Adjusted } \\
\mathrm{R} \\
\text { Square }\end{array}$ & $\begin{array}{r}\text { Std. Error of } \\
\text { the Estimate }\end{array}$ \\
\hline 1 & $.355^{\mathrm{a}}$ & .874 & .048 & 41.0428 \\
\hline
\end{tabular}




\begin{tabular}{|c|c|c|c|c|}
\hline \multicolumn{5}{|c|}{ Model Summary $^{\mathbf{b}}$} \\
\hline \multirow[t]{2}{*}{ Model } & $\mathrm{R}$ & R Square & $\begin{array}{c}\text { Adjusted } \\
\text { R } \\
\text { Square }\end{array}$ & $\begin{array}{l}\text { Std. Error of } \\
\text { the Estimate }\end{array}$ \\
\hline & & & & 6 \\
\hline \multicolumn{5}{|c|}{ a. Predictors: (Constant), ROA, DER, UP, EPS } \\
\hline \multicolumn{5}{|c|}{ b. Dependent Variable: UNDERPRICING } \\
\hline
\end{tabular}

(Sumber: output spss)

Dari tabel 8 diketahui bahwa nilai koefisien deternimasi R square sebesar 0,874yang berarti bahwa variabel Debt To Equity Ratio, Earning per Share, Umur Perusahaan, dan Return On Assets dapat menjelaskan variabel Underpricing sebesar $87,4 \%$ sedangkan sisanya $12,6 \%$ dijelaskan oleh variabel lain diluar dari penelitian ini.

\section{B. Pembahasan}

\section{Pengaruh Debt To Equity Ratio Terhadap Underpricing}

Berdasarkan hasil analisis menunjukkan bahwa variabel Debt To Equity Ratio berpengaruh positif terhadap Underpricing artinya adanya hubungan searah yakni ketika Debt To Equity Ratio naik maka Underpricing juga ikut naik.

Semakin besar DER mencerminkan risiko perusahaan yang relatif tinggi, akibatnya para investor cenderung menghindari saham-saham yang memiliki nilai DER yang tinggi. Seperti penelitian yang dilakukan oleh (Resna, 2014) menemukan bahwa DER berpengaruh signifikan positif terhadap underpricing.

\section{Pengaruh Earning per Share Terhadap Underpricing}

Berdasarkan hasil analisis menunjukkan bahwa variabel Earning per Share berpengaruh positif terhadap Underpricing artinya adanya hubungan searah yakni Ketika Earning per Share naik maka Underpricing juga ikut naik.

Berdasarkan teori signaling untuk mengatasi masalah penilaian yang rendah terhadap harga saham, maka perusahaan yang berkualitas memberikan signal bagi investor untuk menunjukkan bahwa perusahaan tersebut memiliki kualitas yang baik. Apabila EPS perusahaan tinggi, akan semakin banyak investor yang ingin membeli saham tersebut sehingga menyebabkan harga saham tinggi. Hasil penelitian (Resna, 2014) dan (Adriyani, Nuraina, \& Murwani, 2018) EPS berpengaruh signifikan positif terhadap Underpricing.

\section{Pengaruh Umur Perusahaan Terhadap Underpricing}

Berdasarkan hasil analisis menunjukkan bahwa variabel Umur Perusahaan tidak terbukti berpengaruh signifikan terhadap Underpricing. Penelitian yang dilakukan oleh (Risqi \& Harto, 2013) telah membuktikan bahwa umur perusahaan tidak terbukti berpengaruh signifikan pada Underpricing.

Umur perusahaan emiten menunjukkan seberapa lama perusahaan mampu bertahan dan banyaknya informasi yang dapat diserap oleh publik. Perusahaan 
yang beroperasi lebih lama mempunyai kemungkinan yang lebih besar untuk menyediakan informasi perusahaan namun tidak menutup kemungkinan bahwa lamanya perusahaan berdiri tidak dapat menjamin ketika sedang melakukan IPO.

\section{Pengaruh Return On Assets Terhadap Underpricing}

Berdasarkan hasil analisis menunjukkan bahwa variabel Return On Assets berpengaruh negatif terhadap Underpricing artinya adanya hubungan berlawanan arah yakni Ketika Return On Assets menurun maka Underpricing akan naik.

Profitabilitas yang tinggi akan mengurangi ketidakpastian perusahaan di masa yang akan datang dan sekaligus mengurangi ketidakpastian IPO, sehingga akan mengurangi underpricing (Kim, Krinsky, \& Lee, 1993). Menurut (Watts \& Zimmerman, 1990) menyatakan bahwa prestasi keuangan, khususnya tingkat keuntungan, memegang peranan penting dalam penilaian prestasi usaha perusahaan dan sering digunakan sebagai dasar dalam keputusan investasi, khususnya dalam pembelian saham. Penelitian yang dilakukan oleh (Gerianta, 2008) dan (Sandhiaji, 2004), telah membuktikan bahwa profitabilitas perusahaan berpengaruh signifikan (negatif) pada Underpricing.

\section{Kesimpulan}

Berdasarkan hasil dan pembahasan pada bab 4 dapat diperoleh simpulan hasil dari penelitian pada X1 menunjukkan bahwa Debt To Equity Ratio berpengaruh positif daan signifikan terhadap Underpricing. Hasil dari penelitian pada X2 menunjukkan bahwa Earning Per Share berpengaruh positif dan signifikan terhadap Underpricing. Hasil dari penelitian pada X2 menunjukkan bahwa Umur Perusahaan tidak berpengaruh signifikan terhadap Underpricing. Dan hasil penelitian pada X4 menunjukkan bahwa Return On Assets berpengaruh negataf dan signifikan terhadap Underpricing. 
Analisis Pengaruh Faktor-Faktor terhadap Underpricing pada Penawaranumum Saham

Perdana Di Bursa Efek Indonesia

\section{BIBLIOFRAFI}

Adriyani, Linda, Nuraina, Elva, \& Murwani, Juli. (2018). Pengaruh Return On Assets (ROA) Dan Earning Per Share (EPS) Terhadap Underpricing Saham Perdana Pada Perusahaan Yang Terdaftar di Bursa Efek Indonesia. FIPA: Forum Ilmiah Pendidikan Akuntansi, 6(2).Google Scholar

Astuti, Nining Puji. (2012). Pengaruh Earning Per Share (Eps), Price Earning Ratio (Per) Dan Debt To Equity Ratio (Der) Terhadap Return Saham Pada Perusahaan Asuransi Yang Terdaftar Di Bursa Efek Indonesia (Bei). Repository Universitas Islam Negeri Sultan Syarief Kasim Riau.

Barusman, Andala Rama Putra, \& YOSHOA, Yoshoa. (2014). Analisis strategi bauran pemasaran terhadap kepuasan konsumen di bubur gabe bandar lampung. Jurnal Manajemen Dan Bisnis, 4(2). Google Scholar

Gerianta, Wirawan Yasa. (2008). Penyebab Underpricing Pada Penawaran Saham Perdana di Bursa Efek Indonesia. Jurnal Akuntansi Dan Bisnis, 3(2), 11-18. Google Scholar

Hayati, Aulya, \& Isynuwardhana, Deannes. (2014). Faktor-Faktor Yang Mempengaruhi Underpricing Pada Penawaran Saham Perdana Di Bursa Efek Indonesia Tahun 2011-2013. EProceedings of Management, 1(3). Google Scholar

Howitt, Dennis, \& Cramer, Duncan. (2017). Research methods in psychology. Pearson Harlow. Google Scholar

Husaeni, Fahrul. (2019). Pengaruh Rasio Pembayaran Deviden, Laba Per Saham Dan Tingkat Pengembalian Aset Terhadap Rasio Harga Saham Perusahaan Lq45 Yang TerdaftarOdi Bursa Efek indonesia Periode 2012-2018. Repository Universitas Komputer Indonesia. Google Scholar

Indarto, Stefani Lily, \& Ghozali, Imam. (2016). Fraud diamond: Detection analysis on the fraudulent financial reporting. Risk Governance \& Control: Financial Markets \& Institutions, 6(4), 116-123. Google Scholar

Kim, Jeong-Bon, Krinsky, Itzhak, \& Lee, Jason. (1993). Motives for going public and underpricing: New findings from Korea. Journal of Business Finance \& Accounting, 20(2), 195-211. Google Scholar

Kristiantari, I. Dewa Ayu. (2013). Analisis faktor-faktor yang mempengaruhi underpricing saham pada penawaran saham perdana di Bursa Efek Indonesia. Jurnal Ilmiah Akuntansi Dan Humanika, 2(2).

Kurniasari, Yunita. (2016). Faktor-Faktor yang Mempengaruhi Tingkat Underpricing Perusahaan Manufaktur yang Melakukan Initial Public Offering yang Terdaftar di BEI Periode 2011-2014. Repository Universitas Muhammadiyah Surakarta. Google Scholar 
Laeli, Sidik Febrianto. (2016). Perbandingan Metode Robust Least Median of Square (LMS) dan Penduga S Untuk Menangani Outlier Pada Regresi Linier Berganda. Repository Universitas Negeri Semarang. Google Scholar

Resna, Pebriana Fajar. (2014). Fenomenaunderpricing Pada Saat Initial Public Offering (Ipo) Di Jakarta Islamic Index. Fakultas Ekonomi Unissula. Google Scholar

Risqi, Indita Azisia, \& Harto, Puji. (2013). Analisis faktor-faktor yang mempengaruhi underpricing ketika Initial Public Offering (IPO) di Bursa Efek Indonesia. Diponegoro Journal of Accounting, 398-404. Google Scholar

Sandhiaji, Bram Nugroho. (2004). Analisis Faktor-Faktor Yang• Mempengaruhi Tingkat Underpricing Pada Penawaran Umum Perdana (Ipo) Periode Tahun 1996-2002 (Studi Kasus Pada Perusahaan Manufaktur Yang Go Publik Di Bursa Efek Jakarta Tahun 1996-2002). program Pascasarjana Universitas Diponegoro.

Sutanto, Sutanto, Ghozali, Imam, \& Handayani, Rr Sri. (2018). Faktor-Faktor Yang Memengaruhi Penerimaan Dan Penggunaan Sistem Informasi Pengelolaan Keuangan Daerah (Sipkd) Dalam Perspektif the Unified Theory of Acceptance and Use of Technology 2 (Utaut 2) Di Kabupaten Semarang. Jurnal Akuntansi Dan Auditing, 15(1), 37-68. Google Scholar

Watts, Ross L., \& Zimmerman, Jerold L. (1990). Positive accounting theory: a ten year perspective. Accounting Review, 131-156. Google Scholar

Wijayanto, Andhi. (2010). Analisis pengaruh ROA, EPS, financial leverage, proceed terhadap initial return. JDM (Jurnal Dinamika Manajemen), 1(1). Google Scholar

\section{Copyright holder:}

Moch. Irfandi, Sri Muljaningsih, Kiki Asmara (2021)

First publication right:

Syntax Idea

This article is licensed under:

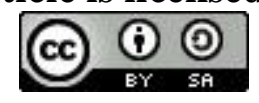

